\title{
Uma nova espécie de Aniba (Lauraceae) da Amazônia
}

\author{
Klaus Kubitzki ( $\left.{ }^{(}\right)$ \\ William A. Rodrigues $\left({ }^{* \hbar}\right)$
}

\begin{abstract}
Resumo
Uma nova espécie de Lauraceae (Aniba lanci¡olia Kubitzki \& Rodrigues), até então só conhecida de uma campina localizada no $\mathrm{Km} 130$ da es. trada Manaus-Caracaraí, é descrita como nova para a Amazônia brasileira, tendo como uma de suas características mais marcantes o hábito arbustivo.
\end{abstract}

\section{INTRODUÇÄO}

A espécie que ora apresentamos como nova, até aqui só conhecida de sua localidade tipica, numa campina de pedras areníticas, situada no Km 130 da estrada Manaus-Caracaraí (BR-174), é marcante por sua forma de crescimento: não se conhece até hoje algum outro membro do gênero Aniba, cujo hábito de croscimento seja arbustivo. Este tipo de hábito, aliás, é mesmo extremamente raro dentro da familia inteira das Lauraceae; os únicos exemplos nas Regiôes Neotropicais, que vêm a nossa mente são Aioua densiflora Nees $l=A$. scandens Ducke) e as espécies aliadas do Nordeste brasileiro. Além do mais, esta nova espécie é única dentro do gênero Aniba que possui folhas com a base amplamente cordada.

A campina onde foi encontrada a presente espécie nova possui uma vegetação sui generis, que merecia ser preservada de qualquer modo como uma relíquia, devido não só às características muito peculiares de sua vegetação como pela riqueza de endemismos e espécies raras.
Infelizmente, já vem sendo irreparavelmente destruída como tantas outras nessa Amazônia imensa sem que alguma coisa pudesse ser feita para proteção do pouco que ainda resta.

\section{DESCRIÇÃo}

Aniba lancifolia Kubitzki \& Rodrigues, n. sp. (Fig. 1 a-h.)

Frutex valde ramificatus usque ad $1,5 \mathrm{~m}$ altus. Ramuli glaberrimi, grisei, longitudinaliter sulcati. Folia alterna, coriacea, ovato-lanceolata, $5.15 \mathrm{~cm}$ longa, $2-5 \mathrm{~cm}$ lata utrinque glabra, basi cordata, rotundata vel late obtusa. apice breviter (per $0,3-0,8 \mathrm{~mm}$ ) acuminata, nervo mediano costisque supra vix elevatis subtus prominulis et venis reticulatis supra inconspicuis subtus prominulis praedita; costae utrinque $9-12$ adscendentes et marginem versus arcuato-connexis; petioli crassi, canaliculati, $0,4-0,6 \mathrm{~cm}$ longi. Paniculae axillares tunues laxe pilosae usque ad $18 \mathrm{~cm}$ longae; bracteae lanceolatae, caducae. Flores per 6 $12 \mathrm{~mm}$ pedicellati, dense et minute sericeotomentelli, sub anthesi campanulati, $2,5 \mathrm{~mm}$ longi et $2 \mathrm{~mm}$ lati; tubus supra haud constrictus, $1,5 \mathrm{~mm}$ longus, intus sericeus. Tepala erecta, inaequalia circiter $11 / 4 \mathrm{~mm}$ ionga exteriora concava, ovata, apice acuta ve! obtusa, $2 / 3 \mathrm{~mm}$ lata, interiora subrotundata,

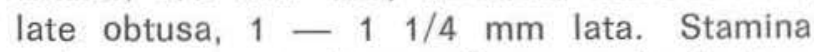
inclusa, $1-11 / 4 \mathrm{~mm}$ longa, antheris fere glabris gradatim in filamenta duplo longiora

(*) - Institut für Allgemeire Botanik und Botanischer Garten, Universität Hamburg, FRG.

(**) - Instituto Nacional de Pesquisas da Amazônia. 

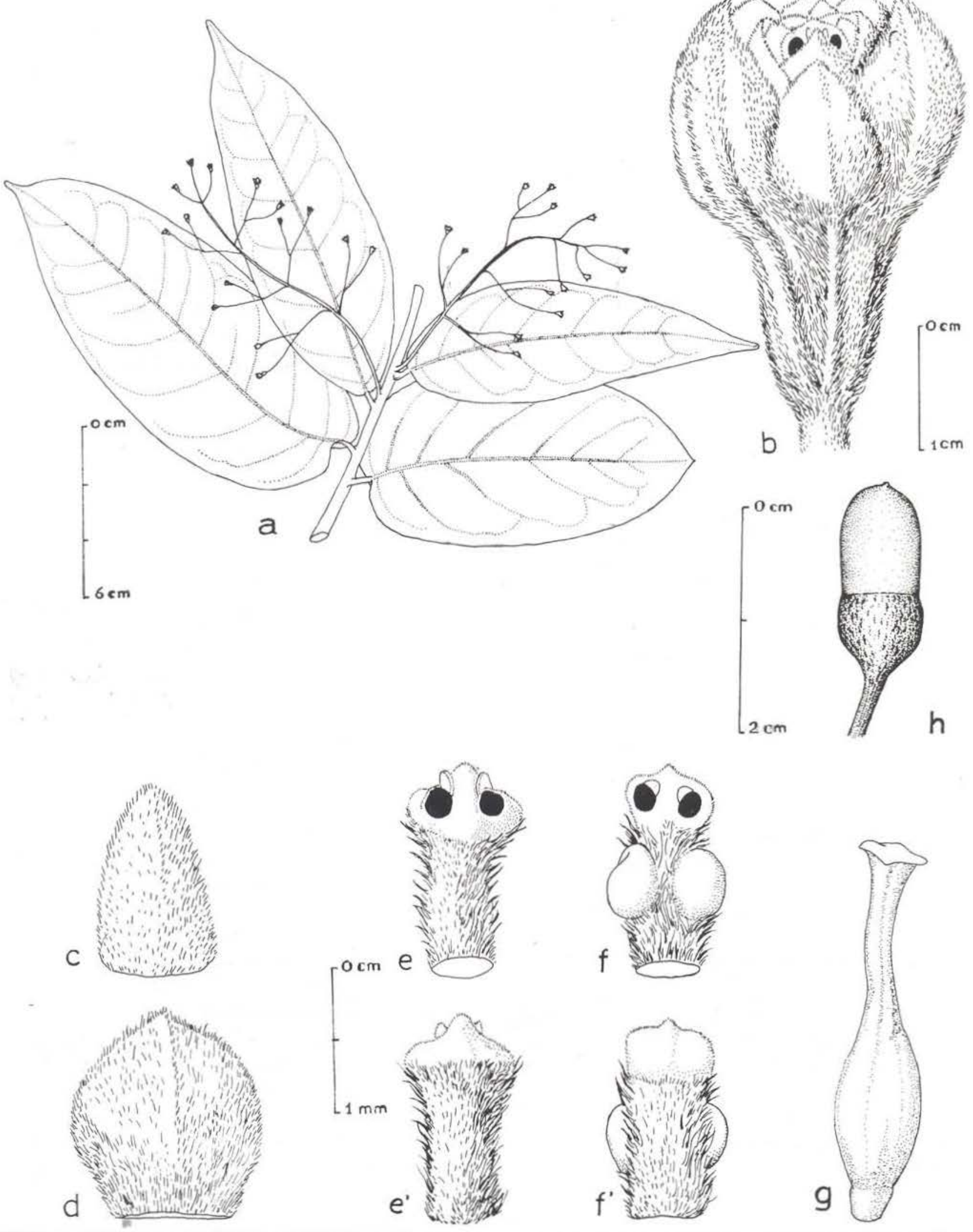

Fig. 1 - Aniba lancifolia Kubitzki \& Rodrigues, n. sp.. a - Raminho florifero; b - Flor; c - Tépala ex. terna; d - Tépala interna; e - Estame, série II, ventral; e' - Estame, série II, dorsal; $\mathfrak{f}$ - Estame, série III, ventral com glândulas anexas; $\mathrm{f}^{\prime}$ - Estame, série III, dorsal; g - Pistilo; $\mathrm{h}$ - Fruto. 
hirsuta transeuntibus praedita, exteriora subincurva, connectivo obtuso producto, interiora connectivo vix producto, filamentis dorsaliter glandulis globosis glabris sessilibus instructa; locelli magni. Staminodia nulla. Cupula rubra cyathiformis, gradatim in pedicellum contracta, ca. 5-6 $\mathrm{mm}$ longa, 6-7 $\mathrm{mm}$ lata extus laxe verruculosa. Bacca oblonga, atropurpurea 12-15 $\mathrm{mm}$ longa, 5-8 $\mathrm{mm}$ lata.

Typus: W. Rodrigues, A. Loureiro \& D. Coelho 9309, Brasil, Amazonas, estrada Manaus-Caracaraí $\mathrm{Km}$ 130, Campina das Pedras, em 25/V/1974 (INPA 43497).

\section{MATERIAL DE REFERÊNCiA}

ERASIL: Estado do Amazonas, estrada Manaus-Caracaraí, Km 130, Campina das Pedras, próximo do igarapé das Lajes: arbusto de $1 \mathrm{~m}$ de altura, ocasional na beira da campina sobre solo de areia branca; folhas verde-claras na página inferior e escuras na superior; botões esverdeados. W. Rodrigues, A. Loureiro \& D. Coelho 9290 , em 25/V/1974 (INPA 43479); - ibid.: arbusto de $1,5 \mathrm{~m}$. de altura, bastante ramificado desde a base; flores amareladas; cúpula vermelha e frutos verdes. W. Rodrigues, A. Loureiro \& D. Coelho 9309 , em 25/V/1974 (holótipo INPA 43.497; isótipo HBG); - ibid.: arbusto de $1 \mathrm{~m}$; flores cremes. J. M. Pires \& P. Leite 14.535 (4), em 19/VI/1974 (HBG; IAN); - ibid.: arbusto de $30 \mathrm{~cm}$ de altura; flores amarelas; frutos, quando maduros, roxo-escuros. O.P. Monteiro \& J. E. Ramos 32, em 6/1/1976. (INPA).

\section{SUMMMARY}

The Authors describe in this paper a new syecies of Lauraceae (Aniba lancifolia Kubitzki \& Rodrigues), to date known only from the type locality in a rocky campina $130 \mathrm{Km}$. N of Manaus, Amazonas. This new species is remarkable for its shrubby habit and its broadly cordate leaf bases. 